\title{
Avaliação da Aprendizagem e Política Educacional: desafios para uma nova agenda
}

ELOÍSA MAIA VIDAL

UECE

ISABEL MARIA SABINO DE FARIAS

UECE

\section{RESUMO}

Este trabalho analisa os resultados do Saeb no decênio 1995-2005, período correspondente a seis aplicaçóes desse exame nacional. A análise objetivou discutir os significados que os indicadores produzidos pelo Saeb permitem extrair sobre a aprendizagem discente no ensino brasileiro, bem como suas implicaçóes na definição de uma agenda política que vise a assegurar o direito à educação, compreendido como o direito de aprender. A reflexão parte do desempenho escolar cearense, analisando-o à luz da situação do Nordeste e do Brasil no período assinalado. Os indicadores revelam que é incipiente a aprendizagem discente na educação básica pública. $\mathrm{O}$ Ceará tem envidado esforços com a finalidade de melhorar a qualidade do ensino alinhado à orientação do MEC, fazendo-se necessário o delineamento de caminhos próprios. A reflexão destaca que a melhoria do ensino está para além do esforço individualizado e abnegado dos docentes, ressaltando o repensar dos rumos da agenda educativa para os próximos anos como um passo ainda necessário para que o direito à educação não seja um privilégio de poucos.

Palavras-chave: política educacional, avaliação da aprendizagem, direito à educação.

\section{RESUMEN}

El trabajo analiza los resultados del SAEB en el decenio 1995/2005, período en el que se aplicó seis veces este examen. El análisis tuvo como objetivo discutir los significados que los indicadores producidos por el SAEB permiten extraer sobre el aprendizaje de los alumnos en la enseñanza brasileña, así como sus implicaciones en la definición de una agenda política que 
pretenda asegurar el derecho a la educación, comprendido como el derecho de aprender. La reflexión parte del desempeño escolar cearense, analizándolo a la luz de la situación no sólo del Noreste sino de todo Brasil, en el período señalado. Los indicadores revelan que es incipiente el aprendizaje de los alumnos en la educación básica pública. Ceará ha realizado esfuerzos con el fin de mejorar la calidad de la enseñanza, siguiendo las orientaciones del Ministerio de Educación y Cultura (MEC), haciéndose necesario el delineamiento de caminos propios. La reflexión destaca que la mejora de la enseñanza está más allá del esfuerzo individualizado y abnegado de los docentes, resaltando el repensar de los rumbos de la agenda educativa para los próximos años como un paso aún necesario para que el derecho a la educación no sea un privilegio de pocos.

Palabras clave: política educativa, evaluación del aprendizaje, derecho a la educación.

\section{ABSTRACT}

This paper analyzes the results of the SAEB national exam during the 1995-2005 period, when six exams were applied. The analysis aims at discussing the conclusions that the SAEB indicators allow to draw about students' learning process in the Brazilian educational system, as well as its implications in defining a political agenda to assure the right to education, here understood as the right to learn. The reflection is based on the school results in the State of Ceará, analyzing them in the light of the situation found not only in the Northeast of Brazil, but also all over Brazil, during that period. The indicators reveal that the learning process is weak in the State's Basic Education system. The State of Ceará has made efforts to improve the quality of its education under the orientation of the Ministry of Education and Culture (MEC), while at the same time highlighting the need to create its own means. The reflection shows that improvement in education lies beyond the individual and abnegate effort of teachers, making clear the need to re-think the aims of the education agenda for the next years as a step to avoid that the right to education be the privilege of a few.

Keywords: education policy, evaluation of the learning process, right to education. 
Declarar um direito é muito significativo. Equivale a colocá-lo dentro de uma hierarquia que o reconhece solenemente como um ponto prioritário das políticas sociais. Mais significativo ainda se torna esse direito quando ele é declarado e garantido como tal pelo poder interventor do Estado, no sentido de assegurá-lo e implementá-lo.

Carlos Roberto Jamil Cury

\section{INTRODUÇÃO}

Este texto analisa os resultados do Sistema de Avaliação da Educação Básica (Saeb) no período 1995-2005 que corresponde a uma série histórica de seis aplicaçóes desse exame nacional. A análise tem como objetivo discutir os resultados obtidos pelo Brasil, pela regiáo Nordeste e pelo Estado do Ceará, tentando extrair significados no que se refere à aprendizagem discente, bem como suas implicaçóes na definição de uma agenda política que vise a assegurar o direito à educação, compreendido como o direito de aprender.

A importância da avaliação da aprendizagem na política educacional brasileira situa-se na década de 1990 quando se inicia um movimento sistemático de reformas no âmbito da América Latina e do Caribe (Silva Júnior, 1999; Peroni, 2003; Dourado; Paro, 2001) em torno de uma política de descentralizaçáo da oferta dos serviços educacionais. No Brasil, foi criado o Saeb, que no decorrer dos anos tem passado por modificaçóes metodológicas no intuito de disponibilizar com mais precisão e clareza, "un retrato extremadamente detallado de las destrezas estudiantiles en Matemáticas y Portugués al final de los grados $4^{\circ}$ y $8^{\circ}$ de la enseñanza primaria y al final del tercer (y último) año de la educación secundaria” (Brooke, 2005, p. 4).

A metodologia de análise utilizada pelo Saeb é a Teoria de Resposta ao Item (TRI), por possibilitar a análise por item e não pela prova como um todo. Para permitir a comparação entre as avaliaçóes aplicadas em anos anteriores nas respectivas séries e disciplinas, são selecionados itens âncoras ${ }^{1}$, que funcionam como elementos que permitem uma avaliação comparada do desempenho dos alunos e o posicionamento numa escala comum.

Uma questão inicial para compreender o tema da presente discussão remete à explicitação do conceito de desempenho escolar e também ao seu significado para a política educativa vigente.

\footnotetext{
${ }^{1}$ Para o Saeb, um item é considerado âncora em um determinado nível, quando "o percentual de acerto do item no nível considerado e nos níveis acima dele é maior que $65 \%$ e o percentual de acerto do item nos níveis anteriores é menor que 65\%” (Brasil, 2002, p. 11).
} 


\section{DESEMPENHO ESCOLAR - UMA NOÇÃO NECESSÁRIA OU HOMOGENEIZADORA?}

A preocupação com a avaliação não é recente, tendo recebido atenção especial nos últimos anos como componente básico da reforma educacional no processo de regulação social. No cenário mundial, essa tendência, reflexo da atuaçáo de organismos internacionais na definição de agendas homogeneizadoras em países latino-americanos, é apresentada como estratégica para a garantia de desenvolvimento consorciado entre as demandas do mercado global e a educação. Este é o tom do discurso do Programa de Promoción de la Reforma Educativa en América Latina y el Caribe (Preal) ao assinalar a "necessidade de contar com mecanismos que permitam produzir informaçóes sobre o que efetivamente se ensina e se aprende nas escolas" (Ravela et al., 2002, p. 6).

$\mathrm{O}$ argumento basilar desse discurso é de que toda política social deve ser avaliada, dela não escapando a educação. Diversas são as críticas a este ordenamento, as quais podem ser sintetizadas nas palavras de Silva Júnior (1999, p. 10), ao lembrar que as agências multilaterais "não apenas afirmam, mas definem critérios, elaboram fórmulas, implantam sistemas. Ao fazê-lo, mobilizam discursos, disponibilizam recursos, privilegiam percursos". A criação do Saeb veio ao encontro destas preocupaçóes, e o conceito de desempenho escolar nele adotado representa uma das variáveis escolhidas para avaliar a Educação Básica brasileira.

No escopo do Saeb, o desempenho escolar é definido como os resultados obtidos pelos alunos do Ensino Fundamental e Médio nas disciplinas de Língua Portuguesa e Matemática. Esses resultados são representados em uma escala de desempenho que descreve, em cada nível, as competências e as habilidades que os alunos são capazes de demonstrar. Essa escala, conforme esclarece o Relatório Nacional do Saeb, possibilita identificar o porcentual de alunos que já construiu as competências e as habilidades desejáveis para cada uma das séries avaliadas, quantos ainda estão em processo de construção, quantos estão abaixo do nível que seria desejável para a série e quantos estão acima do nível que seria esperado (Brasil, 2002, p. 15).

A leitura do desempenho escolar é viabilizada pela utilização de testes elaborados a partir das Matrizes Curriculares de Referência (Brasil, 1999), construída tomando como base descritores que são uma associação entre conteúdos curriculares e operações mentais desenvolvidas pelos alunos (classificação, seriação, causa e efeito, inclusão, correlação, implicação, etc.). Nas Matrizes as competências são classificadas em três níveis distintos - básico, operatório e global - "de açôes e operaçôes mentais que se diferenciam pela qualidade das relaçôes estabelecidas entre o sujeito e o objeto do conhecimento" (idem, p.10). Nas avaliaçóes do Saeb, para os diferentes 
“coorte" definidos $-4^{a}$ e $8^{a}$ séries do Ensino Fundamental e $3^{a}$ série do Ensino Médio - os níveis de ação e operação estão presentes em todos os conteúdos e graus de escolaridade. Assim, um mesmo conteúdo referente a um nível " $\mathrm{x}$ " de escolaridade pode dar origem a descritores de níveis básico, operatório e global. Isso possibilita a construção de um conjunto de itens para um mesmo conteúdo, de forma a distinguir, com maior grau de justiça, o que o aluno já conhece, o que está em via de conhecer e o que ainda náo conhece (ibidem, p. 11-12).

A escala de desempenho em Língua Portuguesa foi dividida em oito níveis e a escala de desempenho em Matemática em dez, organizados de forma cumulativa, isto é, "os alunos posicionados em um nível dominam as habilidades descritas no(s) nível/níveis anterior(es) da escala” (Brasil, 2002b, p.14). Para cada nível é apresentado o porcentual de alunos que dominam as habilidades nele descritas para cada série. No caso de Língua Portuguesa, em cada nível, as habilidades de leitura foram distribuídas nos seis tópicos da Matriz de Referência do Saeb: procedimento de leitura; implicaçôes de suporte, do gênero e/ou do enunciado na compreensão dos textos; relação entre textos; coesão e coerência no processamento do texto; relaçóes entre recursos expressivos e efeitos de sentido; variação lingüística (Brasil, 2002, p. 13).

Segundo o Relatório de Língua Portuguesa de 2001 (Brasil, 2002b), a Matriz de Referência do Saeb, nesta área de conhecimento, está estruturada no foco "leitura", o qual "requer a competência de apreender o texto como construção de conhecimento em diferentes níveis de compreensão, análise e interpretação" (idem, p. 15). Acrescenta, ainda, que os "objetos de conhecimento ou conteúdos" se apresentam como "instrumentos de acesso às competências lingüísticas que o aluno/leitor demonstra por meio de um conjunto de habilidades específicas reunidas no foco da leitura" (idem, p. 15). Em Matemática, a Matriz de Referência do Saeb distribuiu as habilidades em quatro temas: "Espaço e Forma; Grandezas e Medidas; Números e Operaçôes; Tratamento da Informação" (Brasil, 2002a, p. 13).

As tabelas 1, 2 e 3 mostram a relação entre os níveis da escala de desempenho e a proficiência esperada do aluno, para as disciplinas de Língua Portuguesa e Matemática, bem como os níveis de desempenho desejados para cada uma das séries objeto da avaliação.

Como é possível perceber, o conceito de desempenho escolar trabalhado pelo Saeb visa a oferecer elementos mensuráveis e comparativos do aprendizado do aluno em duas áreas básicas do conhecimento. Esta abordagem tem sido alvo de várias críticas, destacando-se aquelas que realçam seu caráter homogeneizador, bem como sua concepçáo comportamentalista e reducionista do que seja aprender (Pozo, 
2002). A questão é polêmica. A seu favor, argumenta-se que ela oferece um parâmetro de análise para conhecer a trajetória de escolarização e de aprendizagem dos alunos no sistema educacional brasileiro.

Tabela 1 - Língua Portuguesa: escala de níveis de desempenho

\begin{tabular}{cc|cl}
\hline Níveis & Proficiência & Níveis & Proficiência \\
\hline 1 & 125 a 150 & 5 & 250 a 300 \\
2 & 150 a 175 & 6 & 300 a 350 \\
3 & 175 a 200 & 7 & 350 a 375 \\
4 & 200 a 250 & 8 & 375 ou mais \\
\hline
\end{tabular}

Fonte: Brasil, 2002b.

Tabela 2 - Matemática: escala de níveis de desempenho

\begin{tabular}{cc|cc}
\hline Níveis & Proficiência & Níveis & Proficiência \\
\hline 1 & 125 a 150 & 6 & 300 a 350 \\
2 & 150 a 175 & 7 & 350 a 375 \\
3 & 175 a 200 & 8 & 375 a 400 \\
4 & 200 a 250 & 9 & 400 a 425 \\
5 & 250 a 300 & 10 & 425 e acima \\
\hline
\end{tabular}

Fonte: Brasil, 2002a.

Tabela 3 - Níveis de desempenho desejados para cada série

\begin{tabular}{l|l|l}
\hline \multicolumn{1}{c|}{ Disciplina } & Série & \multicolumn{1}{c}{ Nível de desempenho esperado } \\
\hline Língua Portuguesa & $4^{\mathrm{a}} \mathrm{EF}$ & Nível 4 e em transição para o 5 \\
Língua Portuguesa & $8^{\mathrm{a}} \mathrm{EF}$ & Nível 6 e em transição para o 7 \\
Língua Portuguesa & $3^{\mathrm{a}} \mathrm{EM}$ & Níveis 7 e 8 \\
Matemática & $4^{\mathrm{a}} \mathrm{EF}$ & Nível 5 e em transição para o 6 \\
Matemática & $8^{\mathrm{a}} \mathrm{EF}$ & Nível 7 e em transição para o 8 \\
Matemática & $3^{\mathrm{a}} \mathrm{EM}$ & Níveis 8, 9 e 10 \\
\hline
\end{tabular}

Fonte: Brasil, 2002.

Num sistema educacional descentralizado como o brasileiro, em que a oferta das diversas etapas da Educação Básica encontra-se distribuída pelos entes federados - Estados e Municípios - não há discordância sobre a necessidade de criação de sistemas nacionais de avaliação. $\mathrm{O}$ ponto nevrálgico desse debate reside na lógica que rege os discursos e os mecanismos implementados. $\mathrm{O}$ argumento de que 
esta é uma "forma de dar maior transparência aos sistemas educativos", bem como torná-los "mais responsáveis perante a sociedade" (Ravela et al., 2002, p. 6), tende a deslocar o centro da responsabilidade pela melhoria da qualidade do ensino para o plano escolar, recaindo esta tarefa principalmente sobre o professor. Contudo, vale lembrar que a crise da escola não é uma crise exclusiva e específica do professor (Farias, 2006). Sáo múltiplos os fatores que intervêm no aprendizado. Melhorar a aprendizagem, a escola, a educação requer, entre outros aspectos, a superação do discurso da "hiper-responsabilização" do professor (Sacristán, 1991), bem como do enfoque "pedagogizante" em torno da qualidade do ensino.

Ao apontar que se aprende cada vez menos, o Saeb revela que embora o problema do acesso ao Ensino Fundamental seja enfrentado pelo País, as questóes relacionadas à qualidade desta oferta continuam a ser um desafio da política educacional para os próximos anos. A necessidade de garantir o direito à educação (Cury, 2002; Oliveira, 2000), isto é, o direito ao conhecimento e às habilidades reclamadas para o pleno exercício da cidadania, numa sociedade tecnológica e com relaçóes de produção globalizadas, persiste como um desafio do século XXI para um país cuja política educacional ainda se debate com problemas como o analfabetismo adulto, altas taxas de reprovação e evasão e precária infra-estrutura de parte do parque escolar. Do contrário, a distância entre quem teve acesso ao saber escolar e quem não teve tende a crescer e a se constituir "em mais-valia intelectual", contribuindo para aumentar a riqueza de pequena parcela da população em detrimento da maioria (Cury, 2002).

\section{INDICADORES DE DESEMPENHO ESCOLAR DO SAEB - CEARÁ, NORDESTE E BRASIL}

O desempenho escolar no Saeb é definido por uma escala que varia de 0 a 500 pontos. Como ela apresenta vários níveis e é de difícil compreensão para os diversos interessados na leitura das informaçóes (especialmente pais e alunos), a partir de 2001 foi estruturado um conjunto de categorias, construído com base nos níveis da escala e associado a estágios de competências para as disciplinas de Língua Portuguesa e Matemática. As categorias de desempenho são: muito crítico, crítico, intermediário, adequado. Tal escala possibilita, portanto, visualizar o perfil de desempenho cognitivo dos alunos, uma vez que aponta os conhecimentos e habilidades relacionados a cada um dos estágios. O que se pôde perceber pelas informaçóes sistematizadas pelo Saeb está detalhado a seguir, considerando as etapas da escolarização avaliadas, o nível desejado para cada uma delas, destacando a situaçáo do Ceará no contexto do Nordeste e Brasil. 


\subsection{4a Série do Ensino Fundamental}

O gráfico 1 mostra o desempenho dos alunos cearenses, nordestinos e brasileiros da $4^{\mathrm{a}}$ série do Ensino Fundamental, em Língua Portuguesa, no decorrer de seis avaliaçóes do Saeb, realizadas no período de 1995 a 2005.

Gráfico 1 - Desempenho em Língua Portuguesa no Saeb 1995-2005 - Brasil, Nordeste e Ceará - 4ª série EF

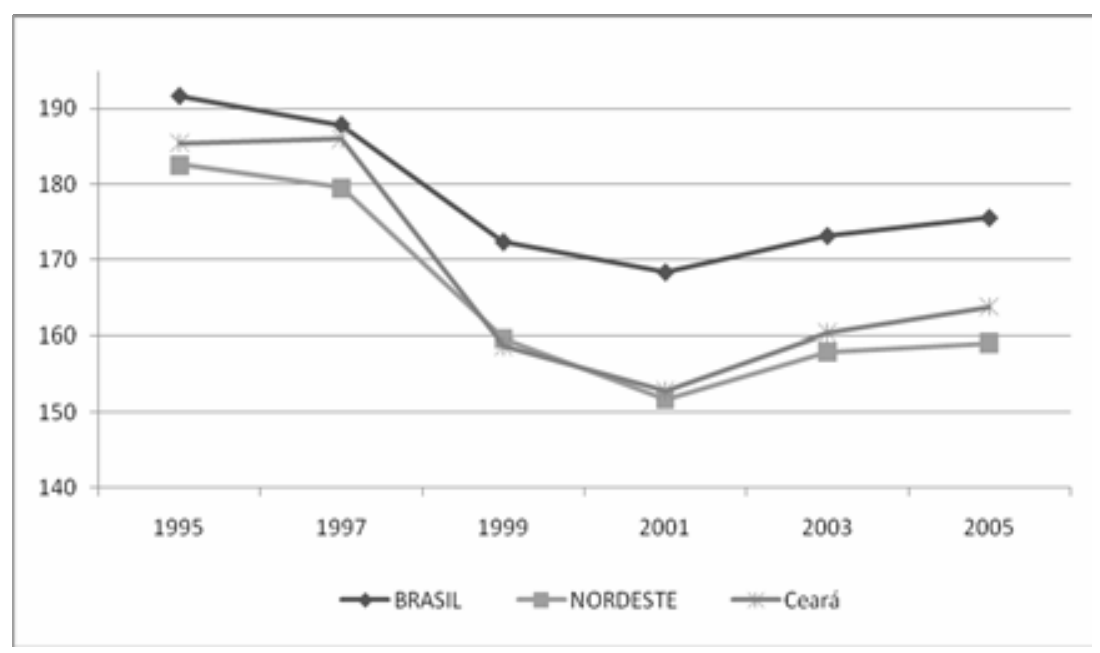

Fonte: Brasil, 2007.

Conforme relatório do Saeb 2005 (Brasil, 2007, p. 9), a média dos alunos cearenses, nesta disciplina e série, foi 163,8 o que indica o domínio de habilidades bem elementares, não correspondendo ao preconizado nas Matrizes Curriculares de Referência (MCR) nem nos Referenciais Curriculares Básicos (RCB) da Secretaria da Educação Básica do Estado do Ceará (Seduc), para quem já cursou 4 anos de Ensino Fundamental. O gráfico 1 permite perceber, contudo, que nos últimos dois exames, o Ceará vem construindo uma trajetória de melhoria no desempenho dos alunos. Tomando as avaliaçóes do período 1997-2001, observase queda cumulativa de $17,8 \%$ na escala de proficiência, fato alterado em 2003, quando se registra crescimento de 5\% em relação a 2001 e mantido em 2005, com um acréscimo de 2,1\% em relação a 2003. Embora os porcentuais de crescimento sejam significativamente inferiores à queda acumulada, mostra a inversão da curva de tendência.

Observando os resultados de Língua Portuguesa em 2005, constata-se que o Ceará, o Nordeste e o Brasil encontram-se em situação semelhante - nível 2 - quando o 
desejado para uma aprendizagem satisfatória é o nível 4, na conclusão deste ciclo de escolaridade. No caso do Ceará, este quadro é ainda mais preocupante ao se desdobrar os resultados por dependência administrativa. Nesse ano, a média dos alunos da rede estadual localiza-se próximo da média nacional (162,3 e 173, respectivamente); sendo a média da rede municipal $14 \%$ menor que a nacional $(148,8)$ e $25,6 \%$ abaixo do valor desejado (200). A rede municipal cearense encontra-se no nível 1, o que corresponde à situação mais elementar da escala de proficiência, com desempenhos mínimos esperados para alunos que estấo concluindo as quatro séries do Ensino Fundamental. Tal situação se coloca como crítica, no caso cearense, pelo fato de o sistema municipal responder por $85 \%$ (800.735 alunos) da matrícula total nesse nível de escolaridade (Seduc, 2006) e por 97,5\% da matrícula da rede pública.

Quando observados sob a ótica dos estágios de competência, os dados da disciplina Língua Portuguesa ${ }^{2}$, em 2003, mostram que o Ceará apresenta um porcentual de alunos, no estágio muito crítico, maior do que o Nordeste e o Brasil - 30,4\%, $29,3 \%$ e $18,7 \%$, respectivamente. Já no estágio crítico, o Estado (41,2\%) situa-se melhor que a regiáo $(41,9 \%)$ e pior que o País $(36,7 \%)$, enquanto no estágio adequado apresenta porcentual que corresponde à metade do escore nacional $(2,4 \% \mathrm{x}$ 4,8\%) (Brasil, 2004a).

O que se pode constatar pelos dados de 2003, da disciplina Língua Portuguesa, é que $71,6 \%$ dos alunos cearenses de $4^{a}$ série encontram-se nos estágios muito crítico e crítico, o que representa $52 \%$ a mais do que o contingente de crianças nessa situação em 1995 (47,1\%). Em 1995, o Ceará tinha 7,92\% das crianças no estágio muito crítico; em 2003 esse indicador chega a 30,4\%, portanto 3,8 vezes o valor de 1995. Crianças nesse estágio não são leitoras fluentes, nem estão devidamente alfabetizadas. A situação não é mais alentadora em relação a Matemática, na mesma série, conforme mostra o gráfico 2 .

O resultado dos alunos cearenses em Matemática, na $4^{\mathrm{a}}$ série, em 2005, embora em processo de crescimento desde 2001, ainda se encontra abaixo dos valores de 1997, quando obteve o melhor desempenho. Desdobrando-se por dependência administrativa, observa-se que a situação de Língua Portuguesa se repete em Matemática, sendo a menor média apresentada pela rede municipal $(152,9)$, enquanto a rede estadual e a particular chegaram aos seguintes resultados - 158,9 e 209,1, respectivamente (Brasil, 2007, p. 10-16). O gráfico 2 mostra que a situação do Ceará é muito semelhante à do Nordeste, enquanto o Brasil apresenta um resultado

\footnotetext{
${ }^{2}$ A análise sobre os estágios de competências se relaciona a 2003, pois até a conclusão deste artigo ainda não tinham sido divulgados os dados de 2005.
} 
$12,1 \%$ maior que o Estado. O resultado do Ceará corresponde a $87,2 \%$ do valor mínimo desejado (250). Na escala do Saeb para essa disciplina, o Ceará encontrase, em 2005, no nível 2, e o Brasil no nível 3, sendo o nível 5 aquele que assegura o domínio de competências e habilidades desejadas no conhecimento matemático, nessa fase do Ensino Fundamental.

\section{Gráfico 2 - Desempenho em Matemática no} Saeb 1995-2005 - Brasil, Nordeste e Ceará - 4a série EF

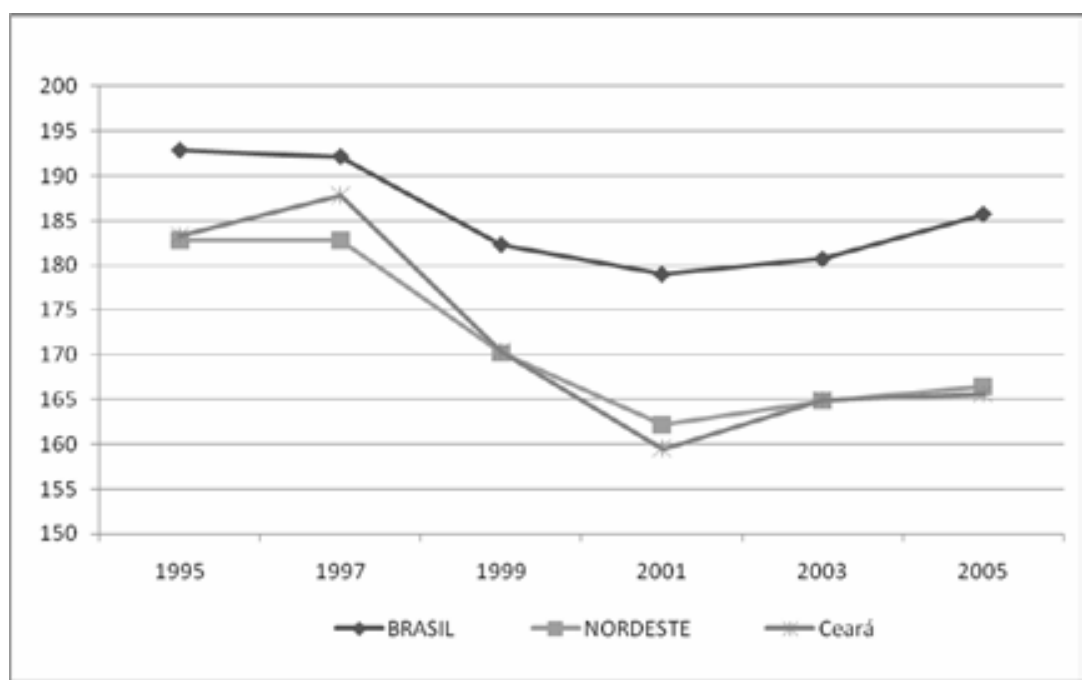

Fonte: Brasil, 2007.

No que diz respeito aos estágios de competências, em 2003, o porcentual de alunos no estágio adequado é muito baixo para os três casos: Brasil (6,4\%), Nordeste $(2,6 \%)$ e Ceará $(3,5 \%)$. No estágio muito crítico, a situação do Estado é pior do que a do Nordeste e do Brasil - 19,4\%, 18,2\% e 11,5\%, respectivamente. Uma criança cujo desempenho se situa nesse estágio "não consegue reconhecer a operação (soma ou subtração) que uma situação problema envolve, da mesma forma que não sabe o significado geométrico de figuras simples" (Brasil, 2003, p.9).

A aprendizagem nas duas disciplinas, na $4^{\mathrm{a}}$ série do Ensino Fundamental, reclama medidas urgentes. Como lembra Ferrão et al. (2001, p. 115), esse período da formação "exerce efeito de longo prazo no percurso escolar dos indivíduos. Um bom aluno nas séries iniciais tem grande chance de ser um bom aluno nas séries seguintes”. Corrobora essa asserção o Relatório de Monitoramento Global (RMG) 2005 (Unesco, 2005) ao destacar que: 
Crianças com baixo desempenho acadêmico podem ser mais vulneráveis à repetência e evasão. Uma vez que a maioria das disciplinas escolares está baseada nos fundamentos introduzidos nas séries iniciais, os alunos de escola primária com baixos níveis de desempenho podem enfrentar dificuldades também nas séries mais avançadas. De fato, resultados de aprendizagem precários nas séries iniciais muitas vezes permitem prever desvantagens educacionais, sociais e econômicas na idade adulta. (p.123, grifos nossos)

Considerando este alerta, cabe verificar o que apontam os indicadores da $8^{\text {a }}$ série desse nível de ensino.

\section{2 $8^{\text {a }}$ Série do Ensino Fundamental}

Os dados obtidos nesta série, em 2005, são provenientes dos alunos admitidos na $1^{\text {a }}$ série do Ensino Fundamental em 1998, primeiro ano de vigência do Fundo de Manutenção e Desenvolvimento do Ensino Fundamental e de Valorização do Magistério (Fundef). Importante destacar que no caso da Regiáo Nordeste, a universalização do acesso à escola fundamental se dá com o advento do Fundef, o que representa um crescimento bastante expressivo de matrículas e, no caso cearense, um acelerado processo de municipalização da oferta, especialmente das séries iniciais dessa etapa de ensino.

Assim como na 4 a série, os resultados dos alunos cearenses em Língua Portuguesa, em 2005, são inferiores aos do Nordeste e do Brasil, embora todos se situem dois níveis abaixo do desejado, como mostra o gráfico 3.

Os resultados por dependência administrativa (estadual, municipal e particular) foram respectivamente: 207,6, 212 e 271,2 revelando, desta feita, que o desempenho da rede estadual é menor do que o da rede municipal. Vale salientar que em 2005, nesta série, as redes municipal e estadual respondem, respectivamente, por $66,4 \%$ e $10,6 \%$ da matrícula total, cabendo à rede particular $22,9 \%$ (Seduc, 2006).

$\mathrm{Na}$ trajetória dos alunos cearenses na disciplina Língua Portuguesa, nos estágios muito crítico e crítico, nota-se que o porcentual de 2003 (33,5\%) ainda se encontra distante dos resultados de 1995 (22,23\%), os melhores já alcançados (Vidal; Farias, 2005, p. 108). O aluno que está em um desses estágios apresenta sérias deficiências de aprendizagem da língua materna. Ele não é um bom leitor, pois embora apresente algumas habilidades de leitura exigíveis para a escolarização no Ensino Fundamental elas ainda estão incompletas (Brasil, 2003a). O gráfico 4 mostra a trajetória 
do desempenho dos alunos de $8^{a}$ série, em Matemática, no Brasil, Nordeste e Ceará. Nele, é possível perceber que, embora com movimentos oscilantes, a queda nos indicadores de aprendizagem apresenta-se como tendência nacional.

Gráfico 3 - Desempenho em Língua Portuguesa no Saeb 1995-2005 - Brasil, Nordeste e Ceará - 8a série EF

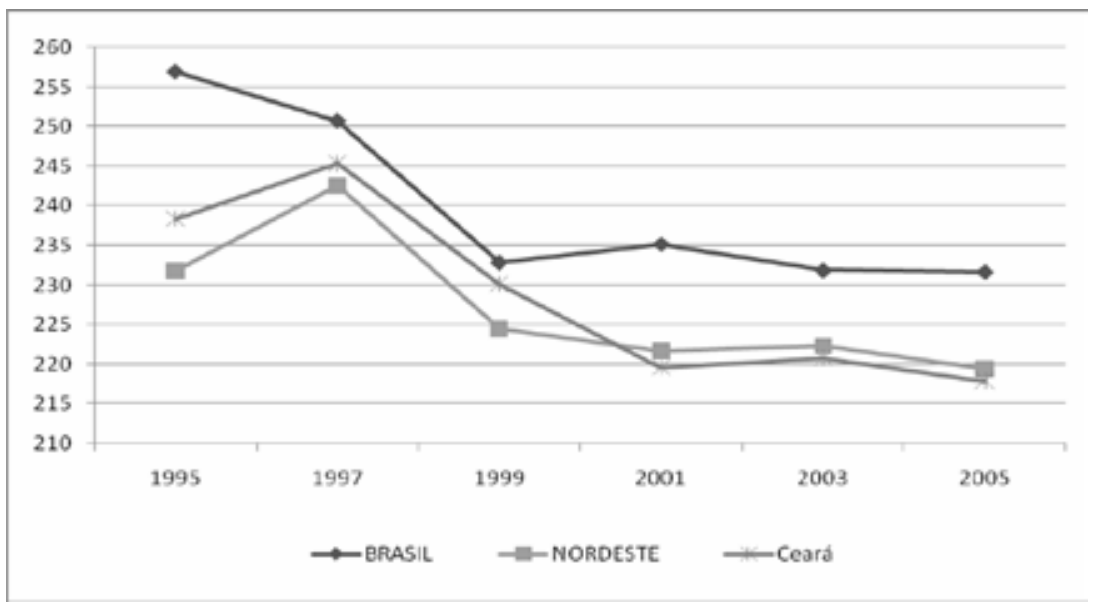

Fonte: Brasil, 2007.

Gráfico 4 - Desempenho em Matemática no Saeb 1995-2005 - Brasil, Nordeste e Ceará - 8a série EF

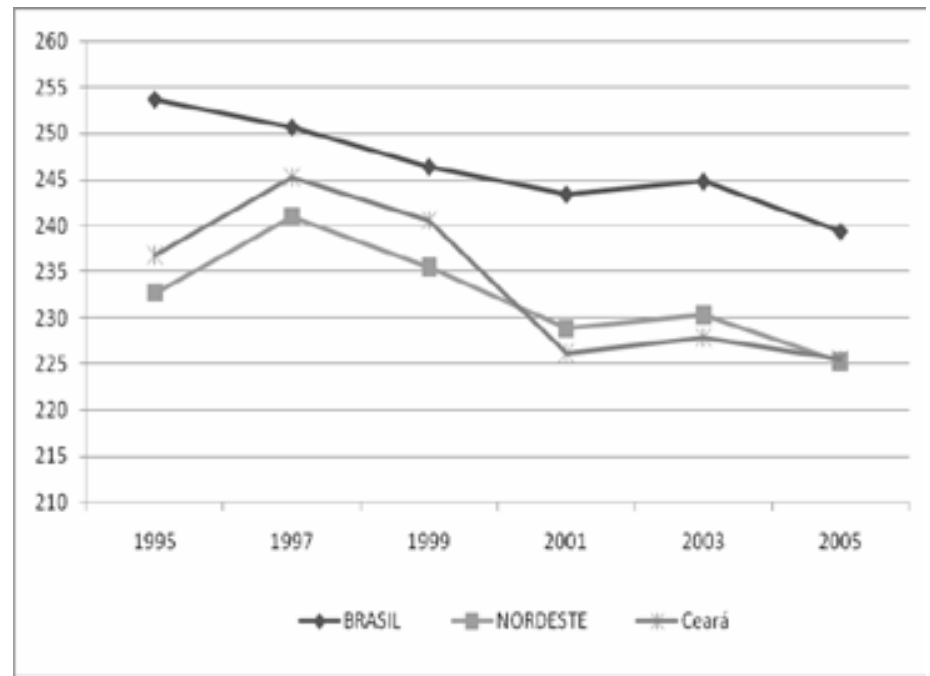

Fonte: Brasil, 2007. 
Os dados de 2005 mostram acentuada proximidade: o Ceará com média 225,5, o Nordeste com 225,2 e o Brasil com 239,4. Se observados os resultados por dependência administrativa, novamente a rede estadual apresenta desempenho inferior à municipal (213,9 x 218,7) (Brasil, 2007, p.29-34). Importante destacar que os resultados das duas redes, no entanto, encontram-se $35,5 \%$ abaixo do mínimo desejado (350).

Para compreender o significado desses indicadores, cabe destacar que os alunos dessa série e disciplina deveriam ser capazes de:

Interpretar e saber resolver problemas de forma competente; fazer uso correto da linguagem matemática específica. Interpretar e construir gráficos; resolver problemas com duas incógnitas utilizando símbolos matemáticos específicos e reconhecer as funções trigonométricas elementares. (Brasil, 2003a, p. 10)

No que se refere aos estágios muito crítico e crítico, a situação do Ceará (11\% e $61,1 \%)$ e do Nordeste (10,9\% e 58,3\%) é muito próxima, e mais distante do Brasil (7,3\% e 49,8\%). No Estado, o porcentual de alunos nesses estágios aumentou de 65,8\% em 1995 para 72,1\% em 2003. Isso significa que eles não desenvolveram habilidades que lhes permitam resolver "expressôes algébricas com uma incógnita, bem como identificar as características e elementos das figuras geométricas planas mais conhecidas" (Brasil, 2003a, p. 10). Os resultados mostram também que o desempenho dos alunos cearenses da rede pública corresponde, praticamente, às propostas curriculares dessa disciplina, previstas para a $4^{\mathrm{a}}$ série do Ensino Fundamental.

A situação do desempenho dos alunos brasileiros em Língua Portuguesa e Matemática no Ensino Fundamental, de modo geral, não é animadora. Embora se observe que todas as regióes geográficas apresentam resultados aquém dos níveis desejados, chamam a atençáo as disparidades entre o Nordeste e Sudeste, que respondem praticamente pela mesma porcentagem de matrículas nessa etapa de ensino (Vidal; Costa; Vieira, 2007), sendo que o Nordeste apresenta, nas duas disciplinas, em 2005, resultados cerca de 20\% inferiores à Região Sudeste.

A série histórica do Saeb aponta a necessidade de políticas que assegurem condiçôes favoráveis à promoção de aprendizagens correspondentes aos domínios cognitivos desejados, especialmente ao longo dos anos de escolaridade do Ensino Fundamental.

A seção seguinte é dedicada à discussão dos indicadores relativos à $3^{a}$ série do Ensino Médio. 


\subsection{3a Série do Ensino Médio}

A oferta de Ensino Médio vem crescendo de forma acelerada, especialmente a partir de 2000, estando nas mãos das redes públicas estaduais o predomínio de matrículas. O desempenho escolar dos alunos desta série, no Saeb, na disciplina Língua Portuguesa, é apresentado no gráfico 5, que mostra sucessivas quedas em 1999 e 2001, com melhoria em 2003, e nova queda nos resultados de 2005. Neste ano, os resultados de Língua Portuguesa revelam que os alunos da $3^{\mathrm{a}}$ série do Ensino Médio do Ceará, do Nordeste e do Brasil encontram-se com déficits de aprendizagem da ordem de $25 \%$ em relação ao mínimo desejado (350). Mantémse também, nesse nível de escolaridade, a tendência nacional de decréscimo nos indicadores de aprendizagem.

Gráfico 5 - Desempenho em Língua Portuguesa

no Saeb 1995-2005 - Brasil, Nordeste e Ceará - 3a série EM

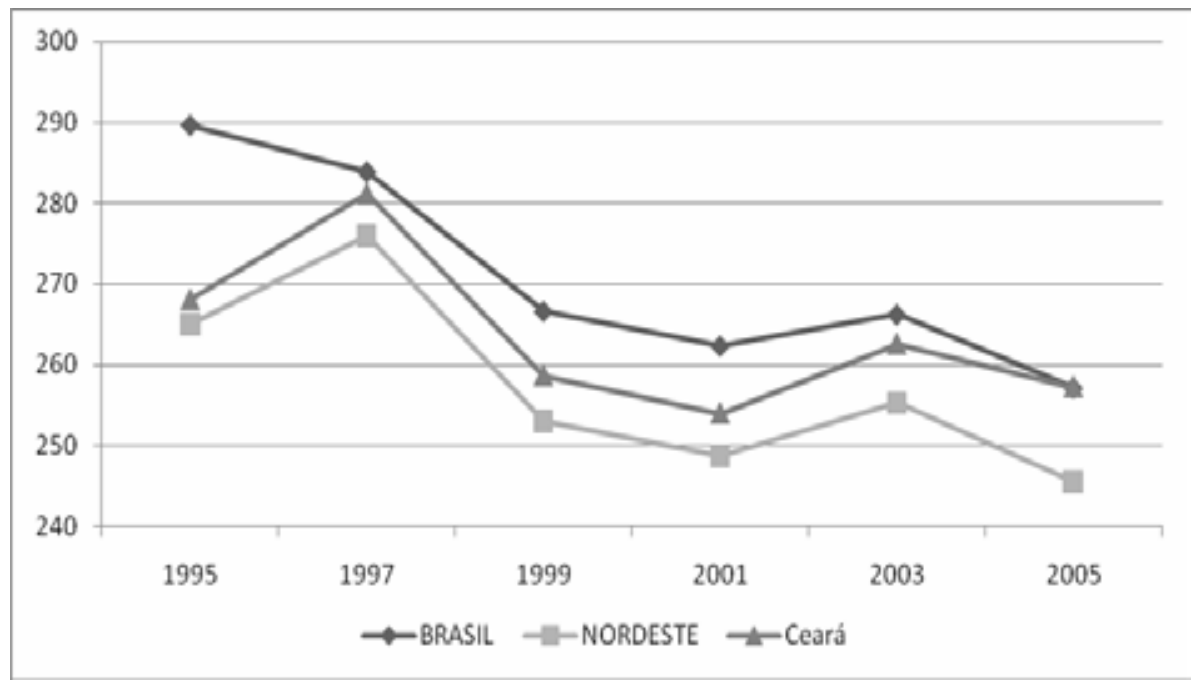

Fonte: Brasil, 2007.

No que diz respeito aos resultados dos alunos que se encontram nos estágios muito crítico e crítico em 2003, observa-se que a situação do Ceará é semelhante à do Brasil com 38,5\% dos jovens nos dois estágios, enquanto o Nordeste apresenta desempenho pior, registrando $48 \%$ dos estudantes na mesma situação. A análise da série histórica mostra que o desempenho dos alunos cearenses já foi melhor: em 1997 apenas 29,5\% estavam nos dois estágios. Esses alunos, portanto, terminam a 
escolarização básica sem desenvolver habilidades de leitura compatíveis com a $4^{\mathrm{a}}$ e a $8^{a}$ séries do Ensino Fundamental. Este quadro aponta a necessidade de um trabalho pedagógico dirigido para práticas de leitura e escrita e desenvolvimento das habilidades de interpretação e compreensão da língua materna.

Quanto a Matemática, a situação de desempenho escolar não é diferente, como mostra o gráfico 6. Exceto o pico de melhoria registrado em 1997, nos demais anos a tendência é de pequenas quedas, com eventuais recuperaçóes, no mesmo ritmo. No Ceará, em 2005, os alunos desta série apresentam resultados 29,3\% inferiores ao mínimo desejado (375).

Gráfico 6 - Desempenho em Matemática

no Saeb 1995-2005 - Brasil, Nordeste e Ceará - 3a série EM

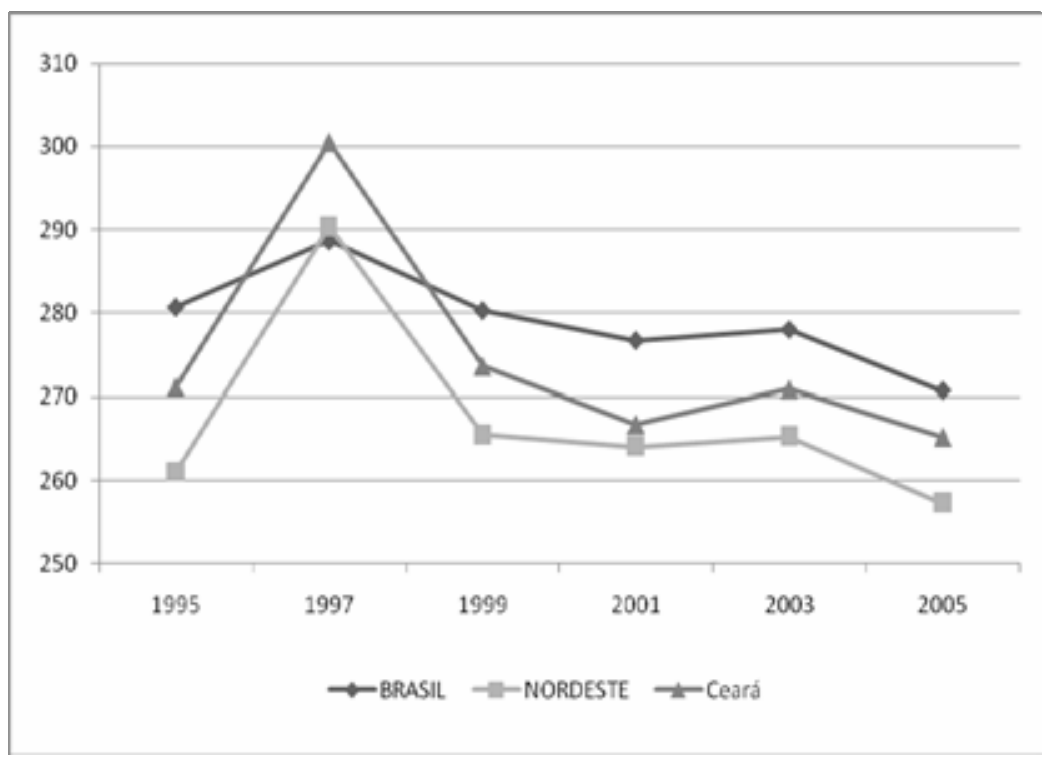

Fonte: Brasil, 2007.

A queda nacional na aprendizagem discente é confirmada. No caso cearense, em Matemática, a proficiência, no período 1997-2001, diminuiu 11,24\%, aumentou 1,7\% em 2003, e caiu 2,1\% em 2005. Para a compreensão desses dados, é preciso ressaltar que as competências previstas para o Ensino Médio estáo situadas nos níveis 8, 9 e 10 da escala do Saeb, em que os estudantes interpretam e sabem resolver problemas de forma competente; fazem uso correto da linguagem matemática específica; apresentam habilidades compatíveis com a série em questão; reconhecem e utilizam elementos 
de geometria analítica, equações polinomiais e desenvolvem operações com números complexos. Além disso, são capazes de resolver problemas distinguindo funçóes exponenciais crescentes e decrescentes, dentre outras habilidades (Brasil, 2003a, p. 11).

Analisando a situação cearense, verifica-se que $73,9 \%$ dos alunos encontram-se nos estágios muito crítico e crítico nesta disciplina, no ano de 2003. Do ponto de vista das competências e habilidades definidas pelo Saeb para a $3^{a}$ série do Ensino Médio, isso significa que a grande maioria apresenta déficits acentuados de conhecimentos matemáticos, tais como:

Desenvolvem algumas habilidades elementares de interpretação de problemas, mas não conseguem transpor o que está sendo pedido no enunciado para uma linguagem matemática específica, estando, portanto muito aquém do exigido para a $3^{a}$ série do E.M. (Construção, leitura e interpretação gráfica; uso de algumas propriedades e características de figuras geométricas planas e resolução de funções logarítmicas e exponenciais). Os alunos, neste estágio, alcançaram os níveis 4 ou 5 da escala do SAEB. (Brasil, 2003a, p.11)

Os indicadores revelam um retrato preocupante do nível de aprendizagem dos alunos, situação presente em todas as etapas da Educação Básica avaliadas pelo Saeb. Exceto para Língua Portuguesa - $4^{\mathrm{a}}$ série, os demais resultados apresentam-se com déficits da ordem de $20 \%$ ou mais em relação aos valores mínimos desejados para as disciplinas e séries. Quais as implicaçôes desse cenário para a agenda educacional dos próximos anos? É sobre esta questão que se detém o próximo tópico, finalizando a reflexão sobre o tema.

\section{DESAFIOS À AGENDA EDUCACIONAL DOS PRÓXIMOS ANOS - ALGUMAS PISTAS}

Na década de 1990, o Brasil, signatário da Conferência Mundial sobre Educação para Todos (1992), em Jomtiem, assumiu compromissos de ampliação do acesso à escola para crianças e jovens. Durante os últimos 15 anos, os esforços têm sido dirigidos a tal propósito e pode-se afirmar que, pelo menos no que diz respeito ao Ensino Fundamental, os patamares atingidos estáo compatíveis com o padrão internacional.

A análise, neste texto, se refere aos dados que procuram idenficar a qualidade dos serviços educacionais, mais especificamente o desempenho escolar dos alunos, ou seja, a aprendizagem cognitiva. O discurso oficial, por algum tempo, procurou associar os resultados do Saeb à acelerada ampliação do acesso, quando da implantaçáo do Fundef (Schwartzman, 2006, p. 14-15). Embora seja patente a precarização do siste- 
ma de ensino, especialmente o público, tal argumento não se sustenta, uma vez que, a partir de 1999, as matrículas do Ensino Fundamental começam a decrescer como mostra a tabela 4, embora os resultados do Saeb continuem caindo até 2001.

Tabela 4 - Matrículas totais no Ensino Fundamental

\begin{tabular}{l|c|r|r|r|r|r}
\hline $\begin{array}{c}\text { Regiões } \\
\text { Geográficas }\end{array}$ & $\mathbf{1 9 9 5}$ & $\mathbf{1 9 9 7}$ & $\mathbf{1 9 9 9}$ & \multicolumn{1}{c|}{$\mathbf{2 0 0 1}$} & $\mathbf{2 0 0 3}$ & \multicolumn{1}{c}{$\mathbf{2 0 0 5}$} \\
\hline Brasil & 32.668 .738 & 34.229 .388 & 36.059 .742 & 35.298 .089 & 34.438 .749 & 33.534 .370 \\
Nordeste & 10.145 .208 & 11.184 .186 & 12.492 .156 & 12.430 .998 & 11.890 .088 & 11.189 .835 \\
Ceará & 1.406 .702 & 1.746 .108 & 1.868 .119 & 1.855 .939 & 1.826 .911 & 1.726 .560 \\
\hline
\end{tabular}

Fonte: Brasil, 2007.

Se os resultados do Saeb não estão relacionados exclusivamente ao aumento de matrículas e às condiçóes estruturais em que tal fato se dá e, se, conforme Sousa (1999), o objetivo precípuo de uma avaliação de sistema é ensejar o desenvolvimento de políticas públicas que assegurem a qualidade do ensino, bem como a igualdade de oportunidades para que todos aprendam, cabe agora investigar que outras variáveis podem estar relacionadas com tais resultados. Assim entendendo, selecionaram-se algumas variáveis apresentadas na tabela 5 que, segundo o Saeb, impactam positivamente no desempenho escolar dos alunos (Brasil, 2002).

Tabela 5 - Variáveis escolares que influenciam o desempenho do aluno, segundo o Saeb 2001

\begin{tabular}{|c|c|c|}
\hline \multirow{2}{*}{ Variáveis } & \multicolumn{2}{|c|}{ Pontuação } \\
\hline & Matemática & Língua Portuguesa \\
\hline Defasagem idade-série & $\begin{array}{l}1 \text { ano }=\text { até } 4,6 \text { pontos } \\
2 \text { anos }=\text { até } 7,7 \text { pontos }\end{array}$ & $\begin{array}{l}\text { Essa variável tem efeito negativo } \\
\text { sobre o desempenho dos alunos }\end{array}$ \\
\hline Diretor com nível superior & $\begin{array}{l}4^{\mathrm{a}} \mathrm{EF}=2,3 \text { a } 12,1 \text { pontos } \\
8^{\mathrm{a}} \mathrm{EF}=1,6 \text { a } 12,3 \text { pontos } \\
3^{\mathrm{a}} \mathrm{EM}=2,1 \text { a } 12,0 \text { pontos }\end{array}$ & $\begin{array}{l}4^{\mathrm{a}} \mathrm{EF}=10,9 \text { pontos } \\
8^{\mathrm{a}} \mathrm{EF}=3,5 \text { a } 13,2 \text { pontos } \\
3^{\mathrm{a}} \mathrm{EM}=4,8 \text { a } 14,7 \text { pontos }\end{array}$ \\
\hline $\begin{array}{l}\text { Professor com nível } \\
\text { superior }\end{array}$ & $\begin{array}{l}4^{\mathrm{a}} E F=3,8 \text { a } 9,4 \text { pontos } \\
8^{\mathrm{a}} E F=7,0 \text { pontos } \\
3^{\mathrm{a}} E M=2,4 \text { pontos }\end{array}$ & $\begin{array}{l}4^{\mathrm{a}} E F=3,3 \text { a } 10,3 \text { pontos } \\
8^{\mathrm{a}} \mathrm{EF}=2,7 \text { a } 8,2 \text { pontos } \\
3^{\mathrm{a}} \mathrm{EM}=3,2 \text { pontos }\end{array}$ \\
\hline Salário do professor & $\begin{array}{l}4^{\mathrm{a}} \mathrm{EF}=2,2 \text { a } 3,7 \text { pontos } \\
8^{\mathrm{a}} \mathrm{EF}=1,1, \text { a } 7,1 \text { pontos } \\
3^{\mathrm{a}} \mathrm{EM}=2,9 \text { a } 11,1 \text { pontos }\end{array}$ & $\begin{array}{l}4^{\mathrm{a}} E F=2,1 \text { a } 4,0 \text { pontos } \\
8^{\mathrm{a}} E F=1,1 \text { a } 4,7 \text { pontos } \\
3^{\mathrm{a}} \mathrm{EM}=2,1 \text { a } 8,6 \text { pontos }\end{array}$ \\
\hline $\begin{array}{l}\text { Desenvolvimento do } \\
\text { conteúdo programático }\end{array}$ & $\begin{array}{l}4^{\mathrm{a}} \mathrm{EF}=3,4 \text { a } 9,4 \text { pontos } \\
8^{\mathrm{a}} \mathrm{EF}=2,2 \text { a } 14,6 \text { pontos } \\
3^{\mathrm{a}} \mathrm{EM}=2,6 \text { a } 20,2 \text { pontos }\end{array}$ & $\begin{array}{l}4^{\mathrm{a}} \mathrm{EF}=2,8 \text { a } 8,9 \text { pontos } \\
8^{\mathrm{a}} \mathrm{EF}=1,4 \text { a } 9,8 \text { pontos } \\
3^{\mathrm{a}} \mathrm{EM}=12,7 \text { pontos }\end{array}$ \\
\hline
\end{tabular}

Fonte: Brasil, 2002. 
O Saeb (Brasil, 2003) aponta que "alunos que cursam uma série com idade superior à ideal têm maiores probabilidades de apresentar diminuição no seu desempenho" (p.126). No caso cearense, em 1998, nas duas redes públicas, em todas as séries, os porcentuais de distorção eram superiores a 45\% (Vidal; Farias, 2005, p.122). Para enfrentar esse desafio, a Secretaria da Educação do Estado implementou o Programa de Classes de Aceleração ${ }^{3}$ visando a corrigir a distorção idade-série nos 6 primeiros anos do Ensino Fundamental. O resultado dessa medida de correção do fluxo escolar tornou-se visível nos porcentuais de evolução da distorção idade-série no período de 1998 a 2005. Embora a rede estadual tenha apresentado evolução bastante significativa nesse período (de $65,1 \%$ para $40,8 \%$ ), a rede municipal respondeu melhor ao desafio de redução da distorção idade/série, especialmente nas séries iniciais (idem, p.123). No Ensino Médio, dados do Inep indicam que a idade média para ingresso na $1^{\text {a }}$ série caiu de 18 anos em 1999, para 17 anos em 2001. A idade média de conclusão desse nível de ensino, na rede pública cearense, era 21 anos em 1999 e 20 anos em 2001. Todavia, a correçáo da distorção idadesérie, nesse nível de ensino, exige a reduçáo das taxas de abandono e de reprovaçáo que, em 2005, somaram 30,1\% (ibidem, p. 123-124).

É preciso considerar que qualquer ação para corrigir a distorção idade/série implica um planejamento em médio prazo, com investimentos significativos, tanto na produção de materiais específicos para esse fim e na constituição de classes especiais quanto na formação dos profissionais que nela atuarão. Sem esse investimento, a adoção de programas, mesmo com eficácia comprovada em outros contextos, tende a não produzir os avanços esperados. Além disso, no caso do Ceará, onde o processo de municipalização do Ensino Fundamental está bastante avançado - a rede municipal responde por $97 \%$ das matrículas públicas nas séries iniciais e por $74,3 \%$ nas séries terminais (Seduc, 2006) - , iniciativas governamentais com esse fim pressupóem a construção de um regime de colaboração Estado-Município, pactuados formal e politicamente.

Quanto à exigência de formação em nível superior, interpretação equivocada da LDB disparou verdadeira corrida de obstáculos entre os professores efetivados na rede. Em regimes emergenciais, abreviados, como projetos de inovaçóes pedagógicas, proliferaram pelo Brasil afora cursos de licenciatura plena. O Ceará náo escapou a esse movimento, disseminando-se cursos superiores em regime especial (realizados nos fins de semana e férias escolares, cursos semipresenciais), na sua quase

\footnotetext{
${ }^{3}$ Esse Programa foi realizado nas duas redes, numa iniciativa de parceria entre Estado e Municípios.
} 
totalidade de Pedagogia, em grande parte dos municípios cearenses. A evolução do quadro de docentes com nível superior atuando no Ensino Fundamental no Ceará pode ser visualizada na tabela 6 .

Tabela 6 - Funções docentes com nível superior - Ensino Fundamental/Ceará

\begin{tabular}{c|c|c|c|c}
\hline Ano/Etapa & $\mathbf{1}^{\mathbf{a}}$ a 4a série & $\mathbf{5}^{\mathbf{a}}$ a 8a série & Total & \% em relação ao Total \\
\hline 1995 & 2.363 & 6.640 & 55.266 & 16,3 \\
2000 & 5.470 & 7.785 & 94.837 & 24,5 \\
2005 & 21.754 & 27.597 & 72.992 & 67,6 \\
\hline
\end{tabular}

Fonte: Brasil, 2008.

A considerar os resultados apresentados pelo Saeb no que tange à formação docente em nível superior como fator de melhoria da aprendizagem dos alunos, no período 1995-2005, os dados cearenses conduzem a um paradoxo. Como explicar o crescimento do quantitativo de profissionais com formaçáo em nível superior e o decréscimo do desempenho escolar no Saeb? Que explicaçóes podem ser atribuídas a esse fenômeno? Seria a qualidade dos cursos de formação inicial ofertados? Estaria relacionado à proliferação de cursos que, sob a denominação de "inovaçóes pedagógicas", foram oferecidos de forma abreviada e com um projeto pedagógico descontextualizado das demandas próprias da Educação Básica? Para essas indagaçôes ainda não existem respostas conclusivas, e, certamente, há uma confluência de fatores associados ao paradoxo gerado.

O salário do professor é destacado pelo Saeb (Brasil, 2002) como uma variável que contribui positivamente para a melhoria do desempenho do aluno. Dados da tabela 7 mostram a situação salarial dos professores que atuam no Ensino Fundamental e Ensino Médio na região Nordeste, nos últimos anos, após a criação do Fundef. Os dados revelam que houve melhoria crescente até 2002, evidenciando quedas salariais em 2005. De modo geral, observou-se, com a criação do Fundef, um movimento ascendente no salário-médio dos professores, que em momentos anteriores encontrava-se em patamares muito inferiores e apresentavam grandes disparidades no âmbito das redes municipais. O Fundef, além de instituir mecanismos legais como a criação de Planos de Cargos e Carreiras, fez com que os menores valores ficassem em torno de $\mathrm{R} \$ 300,00$.

Além da melhoria salarial propiciada pelo Fundef ser fato recente, há que se considerar que, embora em alguns municípios cearenses o incremento salarial tenha che- 
gado a $1.000 \%$, os valores reais ainda deixam muito a desejar, levando os docentes a assumir dupla e tripla jornada de trabalho para atingir patamares salariais que lhes propiciem condiçóes de vida satisfatórias. A ampliação da jornada de trabalho é, sem dúvida, fator de precarização das atividades docentes, fazendo com que, muitas vezes, os professores utilizem a "teoria do esforço mínimo”“ na prática de sala de aula.

Tabela 7 - Rendimento médio real do professor com nível superior, por ciclos de ensino

\begin{tabular}{l|c|r|r|r|r|r|r|r|r}
\hline \multirow{2}{*}{$\begin{array}{c}\text { Regiões } \\
\text { Geográficas }\end{array}$} & \multicolumn{2}{|c|}{ Ensino Fundamental I } & \multicolumn{2}{c|}{ Ensino Fundamental II } & \multicolumn{3}{c}{ Ensino Médio } \\
\cline { 2 - 9 } & $\mathbf{1 9 9 9}$ & $\mathbf{2 0 0 2}$ & $\mathbf{2 0 0 5}$ & $\mathbf{1 9 9 9}$ & $\mathbf{2 0 0 2}$ & $\mathbf{2 0 0 5}$ & $\mathbf{1 9 9 9}$ & $\mathbf{2 0 0 2}$ & $\mathbf{2 0 0 5}$ \\
\hline Brasil & 655,00 & 904,20 & 873,60 & 978,40 & 1063,70 & 975,30 & 1363,30 & 1314,20 & 1247,20 \\
Norte & 641,90 & 839,70 & 749,20 & 939,40 & 1076,80 & 932,20 & 1232,10 & 1361,80 & 1399,00 \\
Nordeste & 413,20 & 610,40 & 584,00 & 625,80 & 693,60 & 683,90 & 958,60 & 1089,40 & 967,30 \\
Sudeste & 877,00 & 1055,70 & 947,50 & 1204,40 & 1274,20 & 1030,40 & 1572,30 & 1420,70 & 1313,00 \\
Sul & 826,00 & 890,50 & 997,10 & 1047,20 & 977,80 & 1019,20 & 1265,80 & 1197,60 & 1198,40 \\
Centro-Oeste & 816,90 & 1284,30 & 981,40 & 965,30 & 1108,50 & 1171,60 & 1374,70 & 1411,70 & 1478,80 \\
\hline
\end{tabular}

Fonte: Vidal; Costa; Oliveira, 2007.

Segundo o Saeb, o desenvolvimento do conteúdo programático previsto para cada uma das séries se coloca como um aspecto que contribui positivamente para a melhoria do desempenho escolar dos alunos. No Ceará, quando da aplicação do Sistema Permanente de Avaliação da Educação Básica do Ceará (SPAECE) - 2004, foram levantados dados junto a 9.545 docentes que atuavam no Ensino Fundamental e Médio acerca do porcentual de cobertura dos conteúdos previstos

\footnotetext{
${ }^{4} \mathrm{O}$ termo teoria do esforço mínimo é aqui adotado para definir as atividades planejadas e executadas pelo professor no cotidiano da sala de aula e que exigem dele pouco esforço laboral e intelectual. O professor, para minimizar o esforço de sua jornada de aulas diárias, opta por desenvolver atividades docentes em que as demandas intelectuais e didáticas sejam as menores possíveis, como forma de conseguir cumprir toda a jornada diária. Por isso, é tão comum, em pesquisas sobre o funcionamento da sala de aula na Educação Básica, deparar-se com um conjunto expressivo de atividades mecânicas, como cópias, resolução de exercícios, trabalho em grupo, que muitas vezes não contribuem efetivamente para o processo de aprendizagem, mas que ocupam o tempo pedagógico dos alunos, sem representar exigências maiores para o docente. Castro e Ioschpe (2007) citam estudo de escolas brasileiras em que 25 a 50\% do tempo pedagógico dos alunos era gasto com cópias a serem transcritas do quadro de giz, atividade que não tem impacto nenhum sobre a aprendizagem discente (p. 18).
} 
nas disciplinas de Matemática e Língua Portuguesa das séries avaliadas, sintetizados na tabela 8 .

Para efeitos de investigação, os conteúdos foram fracionados em quatro faixas: cobertura menor de $40 \%$, entre $40 \%$ e $60 \%$, entre $60 \%$ e $80 \%$, e mais de $80 \%$ dos conteúdos programados por disciplina e série.

Tabela 8 - Distribuição do porcentual de professores segundo o porcentual de cobertura dos conteúdos previstos

\begin{tabular}{|c|c|c|c|c|c|c|}
\hline \multirow{2}{*}{$\begin{array}{c}\text { Porcentual de } \\
\text { Cobertura dos } \\
\text { Conteúdos Previstos }\end{array}$} & \multicolumn{2}{|c|}{ 4$a^{a}$ série EF } & \multicolumn{2}{|c|}{$8^{\text {a }}$ série EF } & \multicolumn{2}{|c|}{ 3a série EM } \\
\hline & $\begin{array}{c}\% \\
\text { Mat. }\end{array}$ & $\begin{array}{c}\% \\
\text { L. Port. }\end{array}$ & $\begin{array}{c}\% \\
\text { Mat. }\end{array}$ & $\begin{array}{c}\% \\
\text { L. Port. }\end{array}$ & $\begin{array}{c}\% \% \\
\text { Mat. }\end{array}$ & $\begin{array}{c}\% \\
\text { L. Port. }\end{array}$ \\
\hline Menos de 40 & 4,8 & 4,8 & 5,2 & 4,2 & 3,9 & 2,8 \\
\hline Entre 40 a 60 & 28,1 & 28,0 & 24,3 & 22,8 & 15,0 & 15,0 \\
\hline Entre 60 a 80 & 51,6 & 51,6 & 49,0 & 49,2 & 48,7 & 44,6 \\
\hline Mais de 80 & 14,1 & 14,2 & 20,2 & 22,4 & 29,4 & 34,2 \\
\hline Em branco & 1,5 & 1,5 & 1,2 & 1,4 & 2,2 & 3,4 \\
\hline Total & 100,0 & 100,0 & 100,0 & 100,0 & 100,0 & 100,0 \\
\hline
\end{tabular}

Fonte: Pequeno; Silva, 2006.

$\mathrm{Na} 4^{\mathrm{a}}$ série do Ensino Fundamental, nas duas disciplinas, 51,6\% dos docentes admitiram que tinham desenvolvido entre $60 \%$ e $80 \%$ dos temas programados, $14,1 \%$ disseram que haviam trabalhado mais de $80 \%$ do conteúdo previsto e $1,5 \%$ não respondeu ao questionamento. Chama a atenção que $28 \%$ dos professores afirmaram cumprir entre $40 \%$ a $60 \%$ dos conteúdos, o que coloca cerca de $30 \%$ dos alunos da $4^{\mathrm{a}}$ série com significativos déficits de conteúdos ao fim da primeira etapa do Ensino Fundamental. Isso, por si só, já cria dificuldades para a continuidade dos estudos desse grupo de alunos.

$\mathrm{Na} 8^{\mathrm{a}}$ série do Ensino Fundamental, ocorreu uma pequena mudança no porcentual de cobertura nas duas áreas: enquanto $49 \%$ informaram que desenvolveram de $60 \%$ a $80 \%$ dos conteúdos programados, $20,2 \%$ disseram que ministraram mais de $80 \%$ e $1,2 \%$ dos docentes preferiu não responder à pergunta. Observa-se que nesta série o porcentual de docentes que cumpriram entre $40 \%$ a $60 \%$ dos conteúdos é menor que na $4^{a}$ série, mas situa-se, ainda, acima de $20 \%$.

A $3^{\text {a }}$ série do Ensino Médio registrou um maior porcentual de professores entrevistados que conseguiu ministrar acima de $80 \%$ dos conteúdos programados para cada uma das disciplinas. Observando a faixa acima de $60 \%$, constata-se que cerca de $78 \%$ dos docentes afirmaram cumprir mais da metade dos conteúdos das 
duas disciplinas. Essa realidade provavelmente tem implicaçóes com os resultados de desempenho constatados, uma vez que a prova aplicada cobre a totalidade dos conteúdos previstos do currículo oficial. Dessa forma, boa parte dos conteúdos avaliados não foi sequer apresentada aos alunos. Essa constatação vem se repetindo no decorrer dos vários levantamentos realizados pelo SPAECE.

Analisando o comportamento do cumprimento dos conteúdos programáticos durante o Ensino Fundamental e Médio, nas duas disciplinas, constata-se uma evolução porcentual para faixas maiores à medida que vai progredindo a escolaridade do aluno. Lamentavelmente, os déficits de conteúdos registrados ao fim da primeira etapa - 4a série do Ensino Fundamental - deixam danos irremediáveis para todo o processo subseqüente de escolaridade. Vale ressaltar que, em estudos qualitativos realizados sobre a abrangência total dos conteúdos, os depoimentos dos professores revelaram que as dificuldades de aprendizagem dos alunos, provenientes das deficiências acumuladas nas séries anteriores, impediam o avanço da programação prevista, uma vez que os alunos não apresentavam pré-requisitos necessários, sendo esse aspecto mais visível na disciplina de Matemática.

Os desafios apontados pelo Saeb, no Ceará, para que o direito à educação seja garantido, conforme preconizam as Cartas federal e estadual vigentes, certamente solicitam a soma de esforços entre o Poder Público e a sociedade civil. O Poder Público local tem envidado esforços visando a melhorar a qualidade do ensino, orientando-se, normalmente, pelas diretrizes emanadas do Ministério da Educação. É preciso construir caminhos próprios. Mesmo que parte dos problemas identificados pelos indicadores de aprendizagem do Saeb demande intervençôes de cunho pedagógico e que impacte sobre a cultura reinante no espaço escolar e entre seus profissionais, tais açôes, para se tornarem práticas concretas no chão da sala de aula, não prescindem do apoio institucional (físico, financeiro e pedagógico).

É imponderável o papel dos professores no processo de mudança na prática educativa. Isso não se questiona. Todavia, importa não perder de vista o fato de que a mudança educacional náo depende exclusivamente desses profissionais, da sua competência técnica (saber a matéria, saber selecionar conteúdos e métodos), política (participar da gestão escolar, atuando de maneira autônoma, ativa e crítica nas tomadas de decisão) e humana (saber relacionar-se com os alunos, os pais e os colegas, tendo em vista estabelecer um clima favorável à aprendizagem de todos, principalmente dos alunos). Há outros aspectos igualmente relevantes. Como chama a atenção Fernandes (2000, p. 83), "o sucesso da mudança depende, também, de escolhas que envolvem relaçóes de poder e de autoridade, valores e finalidades éticas 
e políticas que transcendem o individual". Reconhecer que o sucesso da mudança está para além do esforço individualizado e abnegado de alguns, em particular dos docentes, solicita um repensar dos rumos (intençóes e açóes) da agenda educativa para os próximos anos.

O Brasil, especialmente durante o século XX, embora tenha se tornado signatário de inúmeros documentos internacionais que fixaram compromissos educativos e estabeleceram dispositivos legais determinando a construção de um sistema público de educação de qualidade para todos, vem, no decorrer de sua história como nação, adotando expedientes de eficácia duvidosa, com o carimbo do curto-prazo e do descompromisso, construindo uma trajetória educativa que pode ser qualificada "como um roteiro de oportunidades perdidas" (Garcia, 2003).

A persistência da dicotomia entre os valores proclamados e os valores reais, recorrendo aos termos de Anísio Teixeira, tem transformado a política educativa em um espetáculo, algo que se deve anunciar como importante, mas que vale o "tempo de um governo". Romper com a adoção de artifícios, visando a criar uma imagem de que muito se faz em termos de política educativa, apresenta-se como passo ainda necessário para que o direito à educação não seja privilégio de poucos.

\section{REFERÊNCIAS BIBLIOGRÁFICAS}

BRASIL. Ministério da Educação. Primeiros Resultados. Médias de desempenhodoSAEB/2005 em perspectiva comparada. Brasília: Inep, 2007. - Ministério da Educação. SAEB. Matrizes Curriculares de Referência. 2.ed. edição. Brasília: Inep, 1999.

- SAEB 2001. Relatório Nacional.

Brasília: Inep, 2002. . SAEB 2001. Relatório Matemática. Brasília: Inep, 2002a.

- SAEB 2001. Relatório Língua

Portuguesa. Brasília: Inep, 2002b.

. Qualidade da Educação: uma nova leitura do desempenho dos estudantes da $4^{\mathrm{a}}$ série do Ensino Fundamental. Brasília: Inep, 2003.

. Qualidade da Educação: uma nova leitura do desempenho dos estudantes da $8^{a}$ série do Ensino Fundamental. Brasília: Inep, 2003a.
.Qualidade da Educação: uma nova

leitura do desempenho dos estudantes da $3^{a}$ série do Ensino Médio. Brasília: Inep, 2004.

Ceará. Brasília: Inep, 2004a. . Censos Escolares 1995, 2000 e 2005.

Brasília: Inep, 2008.

BROOKE, N. Accountability Educacional en Brasil: una visión general. n. 34. PREAL. Diciembre, 2005.

CASTRO, C. M.; IOSCHPE, G. La remuneración de los maestros em América Latina: ¿Es baja? ¿Afecta la calidad de la enseñanza? n. 37. PREAL. Enero, 2007.

CURY, C. R. J. Direito à educação: direito à igualdade, direito à diferença. Cadernos de Pesquisa, n. 116, p. 245-262, jul. 2002.

DOURADO, Luiz Fernandes; PARO, Vitor Henrique (orgs.). Políticas públicas e educação 
básica. 1.ed. São Paulo: Xamã, 2001.

FARIAS, Isabel Maria Sabino.Inovação, mudança e cultura docente. Brasília: Líber Livros, 2006.

FERNANDES, Margarida Ramires. Mudança e inovação na pós-modernidade: perspectivas curriculares. Porto, Portugal: Porto Editora, 2000.

FERRAO, M. E. et al. O SAEB - Sistema Nacional de avaliação da Educação Básica: objetivos, características e contribuições na investigação da escola eficaz. Revista Brasileira de Estudos de População, v. 18, n. 1/2, p. 111-130. jan./dez. 2001.

GARCIA, W. E. Demandas retardatárias em tempos difíceis. Brasília, 2003.

OLIVEIRA, I. A. R. Sociabilidade no liberalismo nascente. Revista Lua Nova, v. II, n.50, p. 160, 2000.

PEQUENO, M. I. C.; SILVA, M. G. C. da. Os Professores cearenses: um retrato esboçado a partir de variáveis investigadas no SPAECE 2004. In: VIDAL, E. M. (org.) Avaliação do sistema e qualidade da educação no Ceará: estudos exploratórios do SPAECE 2004. Fortaleza: Edições SEDUC, 2006.

PERONI, Vera. Política educacional e papel do Estado: no Brasil dos anos 1990. São Paulo: Xamã, 2003.

POZO, Juan Ignácio. Aprendizes e mestres: a nova cultura da aprendizagem. Trad. Ernani Rosa. Porto Alegre: Artmed, 2002.

RAVELA, P. et al. Os Próximos passos: como avançar na avaliação de aprendizagem na América Latina? n. 20. PREAL. Janeiro, 2002.

SACRISTÁN, J. G. Consciência e acção sobre a prática como libertação profissional dos professores. In: NÓVOA, A. (org.). Profissão Professor. Lisboa: Porto Editora, 1991.

SEDUC. Coordenadoria de Planejamento e Políticas Educacionais. Censo Escolar 2005. Fortaleza, 2006.

SILVA JÚNIOR, Celestino Alves. Apresentação. In: SILVA JÚNIOR, Celestino Alves; BICUDO, Maria Aparecida Viggiani (orgs.). Formação do educador e avaliação educacional. São Paulo: Editora Unesp, 1999, p.7-10.

SOUSA, Clarilza Prado. Avaliação da Aprendizagem formadora/Avaliação formadora da aprendizagem. In: SILVA JÚNIOR, Celestino Alves; BICUDO, Maria Aparecida Viggiani (orgs.). Formação do Educador e Avaliação Educacional. São Paulo: Editora Unesp, 1999, p. 141-154.

SCHWARTZMAN, S. Acceso y retrasos en la educación en América Latina. Sistemas de Información de Tendencias Educativas en América Latina (SITEAL). 2006.

UNESCO. Relatório de Monitoramento Global 2005. Educação para todos. O imperativo da qualidade. São Paulo: Editora Moderna, 2005.

VIDAL, E. M.; FARIAS, I. M. S. de. SAEB no Ceará: o desafio de definir o foco na aprendizagem. Gestão para o sucesso escolar. Fortaleza: Edições SEDUC, 2005. p. 93-136.

VIDAL, E.; COSTA, L.; VIEIRA, S. L. Ensino fundamental: fim de um ciclo expansionista? In: Centro de Gestão e Estudos Estratégicos. Análise da Pesquisa Nacional por Amostra de Domicílios - PNAD 2005. Livro 2 - Educação. Brasília: MTE/CGEE, 2007, p. 120-170.

Recebido em: outubro 2007

Aprovado para publicação em: abril 2008

Eloísa Maia Vidal é professora da Licenciatura em Física da Universidade Estadual do Ceará (eloisamvidal@yahoo.com.br); Isabel Maria Sabino de Farias é professora do Mestrado em Educação da Universidade Estadual do Ceará (beiasabino@terra.com.br). 